\title{
Direito e Justiça em Derrida e Levinas
}

\author{
Cláudio Ari Mello*
}

Há um divórcio dissimulado entre direito e justiça na modernidade. Há uma suspeita contra a justiça: o direito a teme, teme sua fragilidade, sua instabilidade, sua imprevisibilidade. $O$ direito reconhece o valor e a dignidade da justiça, mas capitula no intento de alcançar a sua altura e a sua profundeza. Contenta-se com a superfície média e plana da tangibilidade. A justiça só pode ser atingida e só acontece por coincidência e por presunção. En seu ensaio Force de loi: le fondement mystique de l'autorité, escrito para juristas mas também contra juristas, o filósofo argelino Jacques Derrida (1930-2004) toca o cenne dessa desconfrança, fere a ferida desse divórcio: a justiça é louca e implica uma desconstrução da razão do direito. Não é só, a justiça é o incalculável, o que sempre nunca foi visto e surpreende sempre, aquilo para o qual nunca se está antes preparado, aquilo cuja compreensão só pode acontecer no durante da experiência. É ainda mais, porque a justiça porta sim um certo misticismo, um além do racional que no entanto irracional não é. Una ação cuja intenção não pode ser programada e ainda assim deve se realizar.

Sim a abordagem de Derrida quanto à justiça é oblíqua. É, aliás, estranhamente obliqua, talvez até mais estranha do que oblíqua. Estranha no sentido freudiano, de que estranhamos não o desconhecido, mas o conhecido que se revela contra o desejo, que se mostra quando se o pretende oculto. O discurso de Forre de loi é uma desorganização das estruturas racionais do direito que é, ao mesmo tempo, uma revelação da sua própria condição enquanto suposto veículo da justiça. De fato é desconfortável, mas o desconforto é uma etapa inescapável da "desconstrução"

* Doutorando em Teoria do Direto no Curso de Pós.Graduação em Direito da Universidade Federal do Rio Grande do Sul. Professor de Direito Constitucional e Filosofia do Direito do Canpus Uruguajana da PUCRS.

'Jacques Derrida, "Force de loi: le fondement mystique de l'autorité", publicado na Cardozo Law Review, vol. 11, 1990, p. 920 e ss. 
proposta por Derrida. É que a desconstrução desorganiza para revelar, desorganiza ou desarranja o direito para mostrar a sua verdadeira posição em face da justiça, tanto aquilo que não ten sido, o que não tem desejado ser, até o que tem de ser se quiser que aplicar uma norma não seja um ato que só realiza a justiça por presunção ou por coincidência. A abordagem é oblíqua e desconfortável porque não fornece uma resposta conceitual que tranqüilize os espíritos ávidos por segurança e certeza. Faz pior, porque diz mesmo que a resposta terá de ser construída e reconstruída, feita, desfeita e refeita a cada novo ato em que se exige do direito a justiça, e que não é no direito que se encontrará a justiça e nem nesmo há um lugar no mundo onde se possa depositar esse conceito e a ele recorrer na hora desesperada en que ele é necessário.

É claro que tudo isso requer uma ruptura. Usemos uma palavra menos desgastada. Impõe um rompimento contra uma concepção de direito como ordem racional, estável e objetiva de normas de conduta que se põe acima da sociedade que é ordenada. Una ordem que se eleva para além do sujeito ordenador e que se preserva em uma intangibilidade desconfiada. A subjetividade que produz uma objetividade como antídoto contra a subjetividade. Há muita estratégia ardilosa nesse projeto, como todos sabem. Mas há tambén auto-engano, medo e um traço esquizofrênico. O direito é então uma ordem objetiva que se superpõe ao seu criador eque converte o criador em criatura. Kelsen disse isso com todas as letras, o direito é a origem de tudo o que é jurídico, o Estado e a "pessoa" inclúdos. O direito é arbitrarianente criado e então suspenso e posto fora do alcance do sujeito. Mas o projeto só se completa com outro ingrediente. Sexá preciso neutralizar a evocação da justiça que a categoria do direito parece implicar necessariamente. Se não é possível elininar essa evocação historicamente necessátia, é preciso domesticá-la e acomodá-la para evitar a frustração do projeto de ordenação objetiva da sociedade, de expulsão da subjetividade do paraíso na terra. A justiça passa a ser pressuposta na própria razão do direito, ou seja, o direito transforma-se cle próprio, tout court, na justiça. Entre a ordem objetiva de nomas e a planície dos sujeitos está apenas Hermes, um Hermes menor, autolimitado, que mede e fiscaliza o sentido perigoso das palavras. A interpretação é a única via de acesso entre o direito e o sujeito, mas não é um veículo de compreensão e abertura, e sim a instância de controle do criador criado sobre a criatura criadora.

Essa arquitetura, sintomaticamente simples e complexa, está desconstruída em Force de loi. Como se disse, Derrida desorganiza e revela, ou desorganiza para revelar o que está por trás e além da ordem. Ele não tolera que a justiça só se realize por coincidência. Pensa que há nisso uma razão que apenas organiza uma irracionalidade que é uma renúncia da razão à sua própria racionalidade. Uma descrença, uma desesperança e um assombro da razão consigo mesma. Ora, a razão da justiça não pode ser um desalento covarde da subjetividade, cla exige uma entrega e uma exploração corajosa do humano no homem, porque a justiça é o próprio humano. É o próprio do humano. Un direiro sem referência na justiça é como uma dieta para cadáveres. 
Derrida promove o reencontro do direito com o homem na justiça. Assim como Saramago realiza uma metafísica invertida do divino no Eyangelho Segundo Jesiz Cristo, en que Deus transcende sua própria divindade para humanizar-se, em Force de lai o direito transcende a si próprio para (re)encontrar o homem na sua subjetividade. A justiça que se obtém pela desconstrução do direito é a metafísica da orden juridica, é um reencontro transcendental entre o direito, moldado pela pretensão de objetividade da razão juridica moderna, e a subjetividade, como condição de possibilidade da justiça para o homem.

A regra não é eliminada, evitada, repudiada ou ignorada. Ele é posta em épokbè para que a singularidade da situação possa vir à presença sem contrangimentos e restrições. "Um ato que consista simplesnente em aplicar uma regra, executar um programa ou efetuar um cálculo, pode ser considerado legal, conforme ao direito, e pode ser, por metáfora, justo, mas seria erado dizer que a decisão foi justa." $\mathrm{A}$ justiça não pode ser obtida pela mera aplicação da regra senão por metáfora, como diz Derrida, ou por coincidência, como prefiro dizer. A regra necessita ser teassumida, confirmada, ratificada na singularidade da situação, e nesse sentido desconstruf́da e reconstruída a cada decisão. Aquele que age não pode tomar emprestada a razão objetiva pressuposta na norna e considerá-la suficiente à realização da justiça. Se o fizer, terá tealiza do no máxino uma ação legal ou conforme ao direito, e, com sorte, terá feito coincidir o resultado da aplicação da regra com a justiça que a situação exigia. Mas então houve uma renúncia à racionalidade plena e alerta que a ação justa demanda, porque o agente deu-se por satisfeito com a racionalidade objetiva que tomou emprestado à regra e denitiu-se de dar à justiça que a situação exigia uma racionalidade autônoma e plena.

Temos aqui um rompimento profundo com o pensamento jurídico hegemônico. Na superfície, Derrida mostra que a justiça não pode estar na aplicação mecânica de uma regra objetiva preexistente, e mestno a confirmação como justa de uma regra en uma situação concreta não alivia o agente de refazer a confirmação em uma outra situação, que se apresenta como permitindo a mera reprodução da primeira decisão. "Cada caso é outro, cada decisão é diferente e requer uma interpretação absolutamente única, que nenhuma regra existente e codificada pode e nem deve absolutamente garantir." " Vale dizer, ele esclarece que a justiça não pode nunca ser 0 que o discurso jurídico diz que ela deve somente ser: "o momento de decisão entre o justo e o injusto não é jamais assegurado por uma regm." "Ricardo Timm de Souza adverte: "Infinitos precedentes podem se haver dado, precedentes de realização da justiça; a justiça realizada é, porém, sempre única"s.

\footnotetext{
${ }^{2}$ Derrida, Force de loi, p. 960.

Derrida, Force de loi, p. 960.

"Derrida, Force de ló, p. 946.

"Rircardo Timm de Souza, "Î́tica e desconstruçāo", p. 172.
} 
Derrida revela ainda o que está spyept under the mug na razão juridica moderna: uma sólida e mal disfarçada indiferença com a justiça. Sim, porque ao dizer que o justo não está na aplicação da regra, Derrida desconcerta o sentido do justo próprio do discurso jurídico, que é o discurso da equivalência, da justiça como direito. Se o direito é a regra e o justo nunca pode ser apenas a teprodução da regra, então o justo não é a regra e a justiça não é o direito. Nesse sentido, foi mais honesto quem sempre disse que o direito nada tem a dizer sobre a justiça - e não foram poucos - do que aqueles que sustentam o principio da equivalência.

Mas a ruptura com o axioma da conformidade à tegra não é uma aposta na irracionalidade como tanto temem os guardiões da lei e da ordem. Ao contrário, é um convite à exploração racional de uma ação que necessariamente escapa ao cálculo eà programação, e que portanto está sujeita ao risco da irracionalidade. O direito pode apenas garantir a racionalidade da regra, quando muito a racionalidade da aplicação da regra. Se esta é a intenção e o limite do direito, então há coerência e suficiência. Mas se é honestamente proposta a realização da justiça pelo direito, então é preciso ter em mente que a racionalidade da regra e da sua aplicação não garante a racionalidade $\mathrm{da}$ justiça pressuposta na regra e na sua aplicação. Nessa experiência, o direito não pode jamais se manter na esfera da objetrvidade impassivel. $O$ ato de justiça desde o direito exige sempre uma transcendência em relação à norma, e essa transcendência resulta de uma desconstrução do próprio direito enquanto ordem de normas de conduta. Desconstrução que não significa eliminação, evitação ou repúdio, mas confirmação, convalidação e reconstrução através de uma outra racionalidade.

Derrida diz que a justiça contém mesmo um mariz de loucura. E não é só. A justiça deve ser louca pela loucura. É preciso una loucura de justiça. Uma loucura que seja uma sede, uma fome e uma resistência. Uma indignação persistente que mantenha alerta e aberta a tazão. A justiça não pode se dar o luxo da superficialidade e da superfluidade. Não pode se satisfazer em ser coadjuvante do direito. A justiçá não pode ser uma loteria. Ela deve ser o protagonista incansável e insaciável da vida do direito. $O$ uso desse termo fantasmagórico e metafórico - loucura pela justiga - não pode entretanto enganar o leitor: loucura aqui não é o apelo ao irracional no a to de decidir uma questão, não está aqui implícito uma perda de controle da razão e o domínio das paixões. A luta de Derrida é travada contra a lógica dogmática que reduz o direito a una mera reprodução da regra, a uma espécie de tekné, na qual o saber jurídico corresponde a uma episteme asséptica e impessoal, que aplica aos fatos um saber teórico inalterável e desinteressado da singularidade e concrerude subjetivas dos fatos humanos. ${ }^{6}$ Estar louco pela justiça é un estar atento, concentrado e entregue

"Essa denúncia está também contida na mirada sobre a hermenêutica jurídica que Gadamer apresenta em Verdade e Método: "O saber-se da reflexão ética possui, de fato, urna relação para consigo nesmo muito característica. As modificações que Atistóteles apresenta no contexto de sua análise da phronesis são uma demonstração disso. Junto à phronesis, a virtude da 
às circunstâncias subjetivas envolvidas na situação, é recusar-se a decidir un caso com o distanciamento e a impessoalidade implicada na prática de um saber teórico.

A desconstrução derridasiana reverte a indiferença do discurso jurídico acerca da justiça. A justiça extrapola a dimensão meramente conceitual sobre a qual assentouse a razão do direito e incorpora em si o fato humano, na singularidade inconfundivel de tudo o que é humano. ${ }^{7}$ A obliqüidade da concepção de Derrida está justamente na radicalidade que ele confere à dimensão singular da justiça. Como ele diz, é no intervalo entre o direito e a justiça que a desconstrução repõe o humano na experiência da decisão sobre o justo e o injusto, "intervalo que traduz o âmbito propriamente dito do humano."

O fato da singularidade radical da justiça é o centro de gtavidade da concepção de justiça em Derrida. E, ao mesmo tempo, o ponto de intersecção dela con a concepção do filósofo lituano-francês Emmanuel Levinas (1930-1995). A singularidade da justiça é uma imposição da singularidade irrepetivel do outro que nos interpela com a pretensão de ser tratado com justiça. O outro que demanda justiça nunca é o mesmo outro que se beneficiou de um ato de justiça anterior, decidido conforme uma regra ou uma decisão precedente que estabeleceu un princípio de ação. A singularidade do novo outro é que suspende a aplicação da tegra e cobra uma convalidação, uma reafirmação do seu princípio de ação em face da novidade contida neste imprevisivel outto. Esse outro provém de uma outra história, traça uma outra trajetória, está em um outro momento, e portanto requer uma nova experiência. A ação justa não pode ser reproduzida sem um déficit intolerável de "justeza". A analogia nunca é perfeita e a justiça não condiz com aproxinações.

O outro que interpela reclamando justiça é aquele que quer ter sua história ouvida por um ouvinte acolhedor e compreensivo, sem abdicar da sua subjetividade. Eis aqui um novo rompimento com o discurso jurídico moderno. Levinas desnuda a injustiça inerente a toda tematização do outro, ao tratamento que se the dispensa como se ele fosse não mais que un objeto tematizado pela razão do mesmo. Mas o outro que vem à "corte de justiça" é sempre só uma "pessoa de direito". E, no discurso jurídico, a pessoa de direito é sempre uma máscara-persona -, um decalque da pessoa inteira e plena que the subjaz. A pessoa de direito sempre limita, constrange,

ponderaçăo reflexiva, aparece o entendimento (Verständnis). O entendimento (Verständnis) é introduzido como um modificação da virtude do saber ético, na medida em que aqui já năo se trata do eu-mesmo, que deve agir. Segundo isso, 'synesis' significa, inequivocamente, a capacidade do julgramento ético. Elogia-se, portanto, a compreensão de alguén, quando ele, julgando, consegue deslocar-se completamente para a plexa concreção da situação da vida em que o outro tem de atuat. Portanto, também aqui näo se trata de um saber em geral, mas de uma concreção momentânea"; ob. cit, p. 479-480.

${ }^{7}$ Ricardo Timm de Souza, "Ética e desconstrução", p. 164.

"Ricardo Timm de Souza, "Ética e desconstrução", p. 169. 
recorta o humano por trás da máscara. A história nunca pode ser contada por inteiro. A pessoa nunca pode se mostrar plenamente. A "corte de justiça" é um palco onde atores e atrizes interpretam papéis que são caricaturas grosseiras de si mesmos. Para "ascender" à corte é preciso tomar-se um objeto do conhecimento totalizante cả instância jurídica, tornar-se um tema dominável, previsível, calculável, adaptável à regra e ao precedente. É sendo menos humanos que somos bem recebidos na "corte".

A razão do direito moderno é aquela que estabelece una ordem objetiva e calculável porque teme o caos que a abertura à subjetividade implica. A repulsa à subjetividade, a pasteurização do humano, a neutralização do sujeito convertido em objeto no palco jurídico produz tambérn, como efeito colateral igualmente desejado, embora não declarado, o fechamento do direito à justiça. Mas o outro que interpela não quer apenas a aplicação neutra da tegra, ele quer justiça em face da sua singular história pessoal, ele quer contar-se e ser ouvido e acolhido enquanto un sujeito integral que não está limitado e contido por una imagen, a qual está obrigado a representar. Levinas insiste neste ponto: "A neutralização do Outro, que se torna tema ou objecto - que aparece, isto é, se coloca na claridade - é precisamente a sua redução ao Mesmo." "Ou, com mais ênfase:

"Outrem não nos afeta como aquele que é preciso sobrepujar, englobar, dominar-mas enquanto outro, independente de nós; por detrás de toda a relação que com ele possamos manter, ressurgente absoluto. É esta maneira de acolher un ente absoluto que descobrimos na justiça e na injustiça e que o discurso efetua, ele que é sempre ensino. Acolhimento de outrem - o termo exprime uma simultaneidade de atividade e de passividade - que coloca a relação com o outro fora das dicotomias válidas para as coisas: do a priorie do a posteriori, da atividade e da passividade." in

Como sintetiza Ricatdo Timm de Souza, "é contra a indiferenciação do humano elevado ao nível de mero conceito que a exigência proprianente bumana de justiça se propõe." "I O projeto da "teoria da justiça" de Levinas é evidenciar a exigência de eticidade presente no fato do encontro entre humanos, uma eticidade que é uma demanda por justiça em relação ao outro. ${ }^{12}$ A justiça exige "cuidar de quem não escolhi", "assumir uma miséria que não é a minha", "softer pelo outro", "ser:

\footnotetext{
'Levinas, Totalidade e Infinito, p. 31. Ver também do autor Autrement q’être ou Au-delá d 'essence.

11) Levinas, Totalidade e Infinito, p. 76.

"Ricardo Timm de Souza, "Justiça, biberdade e alteridade ética", p. 274.

12 Como diz Antorio Sidekum, "o que há de transcendental e inovador no pensamento de Levinas é o seu caráter ético"; "(a) experiência fenomenológica da satisfaçăo das necessidades
} 
responsável por ele", "suportá-lo, estar en seu lugar, consumir-se por ele". . $^{13}$ evidente que há um contraste abissal da proposição de Levinas com o discurso jurídico moderno. O homem propriamente dito não entra na cena da "corte de justiça". Para ter acesso ao universo objetivo do direito, ele está obrigado a apresentar sua identidade totalizadora e, por isso mesmo, reducionista. O homem em um processo judicial é tão-somente o titular de um direito ou de um dever jurídico, nos estritos limites do fato suposto na hipótese normativa. Ele é apenas o veículo que narra o fato e requer a aplicação da regra correspondente. Nada que exceda o papel antecipadamente reservado é admitido. ${ }^{14}$

A "teoria da justiça" de Levinas propóe o oposto do discurso que fundamenta a moderna cosmologia juridica. Esta sustenta justamente a indiferenciação e a padronização como critérios de justiça. A ética pressuposta é a de tratar todos do mesmo modo, ainda que isso signifique ignorar olimpicamente a radical singularidade da situação humana e a inevitável diferenciação do sujeito. $O$ homem que entra no processo é, entăo, sempre o mesmo - o Mesmo -, nunca pode ser o Outro, não pode fugir ou exceder o modelo que está na base do sistema juridico. Ou seja, o processo judicial é já uma violência ao homcm, que precisa ser menos humano para ser ouvido. Ele é vituma da armadilha da tematização, pois necessita transformar-se en um tema objetivo palatável à linguagem segura e estável do direito.

Levinas pensa a justiça a partir de uma reivindicação ćtica de hospitalidade, de abertura e de acolhida do mesmo em relação ao outro. ${ }^{15} \mathrm{~A}$ assimilação da ética como justça levinasiana no universo jứdico não seria menos que revolucionária, na medida em que supõe uma mudança completa de paradigmas. A renúncia à tematização ou à totalização da pessoa, a acollaida ao xosto do outro enquanto outro, a abertura ao infinito que é o outro, a hospitalidade da subjetividade, importam en re-introduzir o ser humano no discurso jurídico e no ambiente das "cortes de justiça". A concepção de justiça de Levinas é, como a de Derrida, estranhamente oblíqua, tão estranha quanto oblíqua. O viés filosófico que adota expōe sem meias-palavras o reducionismo desumanizante da linguagem e da praxisjurídicas modernas. A expulsão do humano da vida do direito é trazida à tona e denunciada.

e do rompimento do egósmo provoca a primeira experiência ética do ser humano, que ć encontrar-se com a alteridade do outro"; cf. Ettca e alteridade. A subjetividade ferida, p. 152.

13 Paulo César Nodari, "O rosto como apelo à tesponsabilidade e à justiça em Levinas", p. 213/ 214.

14 Esta redução do humano no processo judicial atinge o paroxismo no discurso do direito penal do fato, para o qual o juízo sobre o crime, e portanto o júzo de condenação ou absolviçẫo do rétr, deve ser apenas um juizo sobre o fato bruto, nâo sobre a pessoa que é acusada de tề-lo praticado. t́ claro que esse discurso é uma simplificaçăo teórica que tem como fundamento esse medo de operar com a stbjetividade em julgamentos judiciais, e não acimira que em processos julgados pelo tribunal do júri ele tenha enorme dificuldade de ser compreendido pelos juizes leigos.

${ }^{15}$ Derrida, Adiós a Lévinas, p. 37. 
As teorias da justiça dos dois filósofos psicanalisam o direito e descobrem a função do medo na construção teórica e institucional da ordem jurídica moderna. $O$ divórcio apontado nas primeiras linhas tem sua causa no medo da razão jurídica em relação à singularidade e multiplicidade da subjetividade, à inaptidão para o cálculo e para a previsão è radicalidade ética da justiça. Porém, Derrida e Levinas, cada um a setı modo, propõem uma reconciliação entre direito e justiça. Trata-se de uma reconciliação necessariamente traumática para o direito. Algumas das âncoras conceituais que sustentaram sua estrutura moderna não sobreviverão à teposição da ética da justiça na experiência jurídica. O fechamento à subjetividade e a esquizofrenia da objetividade seguramente não tesistriam ao in fluxo das concepções de justiça dos nossos filósofos. Mas é por uma boa causa. Humanizar a justiça é também re-humanizar o homern.

\section{BIBLIOGRAFIA}

BERNARDO, Fernando. Da responsabilidade ética à ético-politico-jurídica: a incondição da responsabilidade ética enquanto incondição da subjetividade segundo Emmanuel Lévinas (II). Revista Filosófica de Caimbra, vol, 9, n. 17, março de 2002, p. 63-97.

DERRIDA, Jacques. Force de loi - Le fondement mystique de l'autorité. In: Deconstruction and the possibility of justice. Cardozo Law Review, v. 11, 1990, p. 920-1045. . A escritura e a diferenģ̧ São Paulo: Editora Perspectiva, $3^{a}$ edição, 2002. . Adiós a Esmananuel Létinas. Palavra de acogidla. Madrid: Editorial Trotta, 1998.

GADAMER, Hans-Georg. Verdade e Método. São Paulo: Vozes, $3^{a}$ edição, 1999.

LEVINAS, Emmanuel. Totalidade e Infinito. Lisboa: Ediçöes 70, 1980. . Autrement q'être on Au-delá d'essence. Paris; Le Livre du Poche, 2004.

NODARI, Paulo César. $O$ tosto como apelo à tesponsabilidade e à justiça em Levinas. In: Sintese-Revista de Filorofia, vol, 29, n. 94 (2002), p. 191-220.

PELIZZOLLI, Marcelo. Levinas: a reconstrução da subjetividade. Porto Alegre: EDIPUCRS, 2002.

SIDEKUM, Antonio. Ética e alteridade. A subjetividade ferida. São Leopoldo: Editora Unisinos, 2002.

SOUZA, Ricardo Timm de. Justiça, liberdade e alteridade ética. Sobre a questão da radicalidade da justiça desde o pensamento de Emmanuel Levinas. In: Veritas Revista de Filosofia, v. 46, п. 2, jun. 2001, p. 265-274.

Hurnanismo e alteridade - a filosofia frente à radicalidade do desafio humano.

In: O humanismo latino no Brasil de Hoje. Belo Horizonte: PUC-Minas-Extensão, 2001, p. 81-95.

. Ética e descontrução. Justiça e linguagem desde "Force de loi; lê "fondemant mystique de l'autorité", de J, Derrida. In: Veritus - Revista de Filosofia, vol. 47, n. 2, јил. 2002, p. 159-185.

STEIN, Enildo. Diferenfa e Metafisica: Ensaios sobre a desconstrufão. Porto Alegre: EDIPUCRS, 2000.

SUZIN, Luis Carlos. O Homem messianico: Uma introduçáa ao pensamento de E. Levintas Porto Alegre: EST/Vozes, 1984. 